\title{
A New Trend in the Study of Low Back Pain in Workplaces
}

\author{
Sohei YAMAMOTO
}

\begin{abstract}
National Institute of Industrial Health, 21-1, Nagao 6-chome, Tama-ku, Kawasaki 214, Japan
\end{abstract}
Received December 15, 1996 and accepted February 17, 1997

\begin{abstract}
In 1996, the number of low back pain (LBP) cases totaled 5,162 in Japan, accounting for $60 \%$ of the total number of officially recognized cases of occupational diseases. In recent decades, the number of LBP cases, however, has been gradually decreasing. The rate of this decrease is slower in non-manufacturing industries than in other sectors, while the prevalence rate of LBP has tended to increase among workers in tertiary industries in 1995 and 1996. Epidemiological studies have clarified that workplace factors of LBP include not only the handling of heavy materials, but also unnatural postures, sudden and unexpected motions, and individual worker's characteristics. It was, therefore, suggested that comprehensive countermeasures to prevent LBP be undertaken on the basis of work environmental control, work management practice, and health care. The Labor Ministry of Japan issued guidelines for the prevention of LBP in 1994, in which various factors in the work environment, the importance of readiness for motion, standardization of work procedures, and exercise before work were newly outlined. In addition to the psychophysical and biomechanical models of LBP so far reported, established findings of physiological studies on muscle tone and postural reflexes have been conceptually introduced into the guidelines. Such physiological findings are essential for the mechanistic elucidation of work-related LBP and the preparation of its countermeasures, as LBP can also be caused by sudden and unexpected motions as well as various environmental factors. Physical and mental readiness to cope with changes in voluntary motions is a prerequisite for the prevention of LBP in daily work, which constitutes time-sequential changes in posture and motion under various environmental conditions. This paper critically reviews the workplace factors of LBP, its models for evaluating the workload on the body, and environmental risk factors with reference to the neural control of muscle contraction underlying the voluntary motion of workers.
\end{abstract}

Key words: Low back pain, Guidelines, Regulatory standards, Workplace factors, Environmental factors, Working postures, Lumbar spine

\section{Introduction}

In more than 60 countries, low back pain (LBP) has become a major source of occupational health problems. Various countermeasures have been implemented as regulatory guidelines and standards in which the maximum allowable weight of manual material handling and other working conditions have been outlined to prevent $\mathrm{LBP}^{1-9}$. Table 1 shows the number of LBP cases in various sectors of industry from 1987 to 1996, according to the Labor Standards Bureau of the Labor Ministry in Japan ${ }^{10}$. These data show the number of workers who missed four days or more of work because 
Table 1. Annual cases of low back pain in Japan ${ }^{10)}$

\begin{tabular}{|c|c|c|c|c|c|c|c|c|c|c|}
\hline Type of industry $\quad$ Year & 1987 & 1988 & 1989 & 1990 & 1991 & 1992 & 1993 & 1994 & 1995 & 1996 \\
\hline Manufacturing & 2,703 & 2,586 & 2,542 & 2,532 & 2,262 & 2,063 & 1,912 & 1,771 & 1,615 & 1,408 \\
\hline Mining & 249 & 185 & 149 & 91 & 63 & $\underline{69}$ & 52 & 37 & 30 & 21 \\
\hline Construction & 1,320 & 1,175 & $\underline{1,210}$ & 1,068 & 1,009 & 888 & 832 & 719 & $\underline{736}$ & 672 \\
\hline Transportation & 1,820 & 1,624 & $\underline{1,934}$ & 1,805 & 1,557 & 1,316 & 1,292 & 1,232 & 1,130 & 1,016 \\
\hline Cargo handling & 353 & 326 & 227 & 217 & 200 & 295 & 176 & $\underline{190}$ & 136 & 107 \\
\hline Agriculture, forestry, and fishery & 243 & 220 & 223 & 195 & 185 & 165 & 149 & 128 & $\underline{136}$ & 116 \\
\hline Commerce, finance, and advertising & 949 & 840 & $\underline{927}$ & $\underline{991}$ & 872 & $\underline{910}$ & 840 & 772 & $\underline{786}$ & 785 \\
\hline Other industries & 993 & 996 & $\underline{1,069}$ & $\underline{1,082}$ & 1,073 & 1,010 & 1,046 & 990 & $\underline{1,009}$ & $\underline{1,037}$ \\
\hline Total & 8,635 & 7,952 & 8,281 & 7,981 & 7,222 & 6,747 & 6,299 & 5,935 & 5,573 & 5,162 \\
\hline
\end{tabular}

of LBP. The number of LBP cases was greatest in the manufacturing industry, followed by the construction, transportation and commerce, finance, and advertising industries. The number of LBP cases has been gradually decreasing over the past decade, but the rate of decrease differs depending on industry sector. Nonetheless, a temporary increase in the number of LBP cases has been observed as indicated by the underlined data in Table 1. It is noteworthy that the number of LBP cases in "other" industries, including the health service, grocery, and cleaning businesses, increased in the most recent years, 1995 and 1996. When the number of LBP cases was adjusted for the number of workers involved in each industry, the prevalence rate was greater in the non-manufacturing sectors of industry than in the manufacturing sectors ${ }^{11)}$. Therefore, it could not be concluded from the data shown in Table 1 or the published report $^{11)}$ that any specific sector of industry had a higher risk of LBP, because LBP occurred in all sectors of industry, including services, and commerce where no definite decrease in the prevalence of LBP was observed. The cause of workrelated LBP may be attributed to various factors or a combination thereof, including (1) bodily movements at work causing excessive static and dynamic burdens on the waist, (2) work environmental factors such as vibration, cold, lighting and floor conditions, and (3) individual worker's characteristics such as age, gender, body musculature, and medical history.

In 1994, the Labor Ministry of Japan issued new guidelines for the prevention of LBP in workplaces and started to promote LBP prevention instruction among administrative staff and workers ${ }^{12)}$. The basic standpoint in formulating the guidelines was that work-related LBP does not occur with greater prevalence in any specific sector of industry, but rather occurs in all sectors, whether they be highly industrialized or non-industrialized, manufacturing or nonmanufacturing. The preventive countermeasures against LBP formulated in the guidelines are based on the three basic principles of industrial health: environmental control, work practice management, and worker's health care ${ }^{13)}$. The new guidelines are characterized by the adoption of concepts and viewpoints from recent findings in scientific studies on the mechanisms of LBP. This paper deals with the principal viewpoints and basic and applied sciences for the prevention of LBP.

\section{Workplace Factors of LBP}

Workplace factors of LBP have been clarified by epidemiological and field observation studies. According to several reviews ${ }^{14-16)}$, these factors can be classified into the following categories: strenuous physical work, carrying and lifting, static work postures, frequent bending and twisting, external factors such as vibration, slips and falls, and individual workers' characteristics such as age, gender, musculature, and history of diseases.

Table 2 shows the various risk factors of LBP in workplaces, their corresponding LBP prevalence rates, and causative workload variables, which were summarized from several epidemiological studies ${ }^{16-18)}$. The lifting of heavy materials is the highest risk factor of LBP, and its prevalence rate differs from one sector of industry to another, depending on the types of work and working conditions ${ }^{14-16)}$. For example, the prevalence rate was $27 \%$ for the steel industry and $75 \%$ for the transportation industry ${ }^{15}$. Analysis of cases of LBP which has been officially recognized as an occupational injury resulting in four days or more of leave in 1987 and 1989 revealed that the highest risk factor was unnatural work postures (prevalence of $60.2 \%$ ), followed 
Table 2. Workplace factors of low back pain and their corresponding prevalence rates ${ }^{1-7)}$

\begin{tabular}{lrl}
\hline \multicolumn{1}{c}{ Factors } & Prevalence rates & \multicolumn{1}{c}{ LBP-related variables } \\
\hline 1) Lifting & $27-75 \%$ & $\begin{array}{l}\text { weight, distance, speed, acceleration, } \\
\text { holding time, frequency/h, duration/shift } \\
\text { grade of bending (angle on the sagittal plane) }\end{array}$ \\
2) Bending of the trunk & $12-61 \%$ & angle on the horizontal plane \\
3) Twisting of the trunk & $12-18 \%$ & sitting, standing, stooping, kneeling \\
4) Static work posture & $7 \%$ & lighting, floor conditions \\
5) Slip/fall & $3-37 \%$ & driving hours/shift, annual exposure \\
6) Vibration, cold & - & - \\
7) Trauma & $2 \%$ & \\
\hline
\end{tabular}

1) Yu Tak-Sun et al. (1984) $)^{15)}$, 2) Budorf A (1992) ${ }^{16)}$, 3) Buckle PW et al. (1992) ${ }^{18)}$, 4) McAtamny

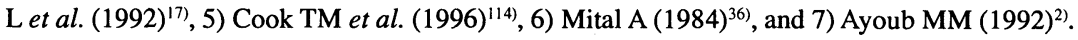

by sudden muscle contraction $(25.9 \%)$, loss of balance (8.2\%), stumbling over obstacles (3.8\%) and unknown causes $(1.8 \%)^{19}$. Unnatural working postures can be classified into static postures such as sitting, standing, kneeling, and squatting, and dynamic postures, that accompany repetitive muscle contraction. Static postures cause a disturbance of peripheral circulation by compressing the blood vessels, easily causing muscle fatigue. Dynamic postures facilitate blood circulation by means of a muscular pump, leading to excessive load on muscles, joints, and tendons. Sudden maximum muscular effort, frequency of handling heavy materials, material weights, and working hours/shift are also important workplace factors. Losing one's balance and stumbling over obstacles are thought to be causally related to environmental factors including lighting, floor conditions, and narrow work spaces. The causal relationship of this factor to LBP should be analyzed in terms of the environmental conditions and individual workers' characteristics.

The mechanisms under which bodily overload is produced by the lifting of heavy materials and unnatural postures have been extensively studied from the standpoint of biomechanics. However, the causes of LBP cannot be explained solely in terms of the biomechanical mechanism, since one third of all LBP cases are associated with the sudden onset of a particular physical activity (prevalence of $31 \%$ ) and the other two thirds (about $60 \%$ ) occur without any notice or recognition of a specific incident ${ }^{15)}$. The latter mechanism will be dealt with in later sections on asymmetric lifting and postural control. According to Yu Tak-sun et al. ${ }^{15)}$ and others ${ }^{5,18,20)}$, the risk factors of LBP that can be categorized into each individual worker's characteristics include age, gender, anthrometry, musculoskeletal abnormality, muscle strength, physical fitness, psychological factors, and previous attacks of LBP.

Several reports suggest that workplace factors of LBP can be classified into commonly recognized categories, and that psychophysical and other criteria can be applied to evaluate these load variables ${ }^{21-24)}$. Anderson ${ }^{25)}$ reported the following vocational risk factors of LBP: heavy physical work, static work posture, frequent bending and twisting, lifting and forceful movements, repetitive work, vibration, and physiological and psychological factors.

In order to establish the maximum allowable weight of manual material handling, experimental studies have been carried out by considering combinations of the following variables: weight, horizontal and vertical location of the object, traveling distance, frequency of lifting, and work duration. The effects of these variables were evaluated by biomechanical and physiological responses and psychological assessment ${ }^{22}$. Recently, efforts have been made to formulate evaluation criteria such as action level (AL) by $\mathrm{NIOSH}^{22)}$, to prevent LBP and thus establish regulatory standards for maximum allowable limits of weight. Such standards are being refined by considering different working postures, the range of work duration and lifting frequency ${ }^{26-28)}$, and task combinations ${ }^{29)}$.

\section{Biomechanics of Spinal Load from Handling Materials}

Many epidemiological studies have recognized the handling of heavy material as a major workplace factor of LBP. According to a field survey ${ }^{30)}$ conducted by the Labor safety and Health Association of Kanagawa Prefecture, LBP occurred most frequently ( $21 \%$ ) during frequent lifting of materials weighing 20 to $29 \mathrm{~kg}$, followed by lifting of materials heavier than $60 \mathrm{~kg}(19.9 \%)$. This indicates that 
an LBP curve peaked at two weight ranges, 20 to $29 \mathrm{~kg}$ and over $60 \mathrm{~kg}$. Lifting of materials heavier than $60 \mathrm{~kg}$ would obviously affect the structure of the lumbar spine, leading mechanically to low back injuries. However, the high prevalence of LBP in the handling of 20 to $29 \mathrm{~kg}^{30}$ material suggests that the marginal safety level for manual material handling should be determined by a combination of various load variables, including unnatural postures and environmental factors.

The fundamental biomechanics of the load of manual material handling on the lumbar spine have been elucidated with reference to a model of the lever, which balances the mass gravity of a material on one arm with the strength of lumbar muscle contraction on the other arm, with the lumbar bone acting as the fulcrum. Biomechanical models have been proposed using force and its moment acting on the lumbar spine in order to determine a marginal safety level ${ }^{31}$ or a maximum acceptable weight (MAW) during manual handling. Ekholm et al. ${ }^{32}$ estimated the compressive loading force on $\mathrm{L}_{5}-\mathrm{S}_{1}$ by taking three types of measurements: (1) EMG activities from the lumbar erector spinae, the rectus and oblique abdominalis muscle, (2) loading moment for $\mathrm{L}_{5}-\mathrm{S}_{1}$ by weight of the body segment, and (3) exertion force upon lifting a box using a strain gauge during whole lifting cycle. The velocity and acceleration of lifting material, e.g., the dynamic force impacted by rapid motion or jerking, were additionally exerted to compressive loading on the lumbar spine $^{33-35)}$. Thus there are four load variables: weight of object, length of arm, vertical distance of movement, velocity and acceleration of handling action ${ }^{21)}$. Furthermore, the frequency of lifting can be related to the total work load on the spine and energy consumption, and the shapes of materials, e.g., with or without a proper handling grip, can affect the total load of manual material handling.

NIOSH guidelines comprise six load variables based on epidemiological and experimental data, using the dynamic model of back and leg lifting on a sagittal plane. These variables are object weight, horizontal and vertical location, travel distance, frequency of lifting, and duration or period. The model was physiologically formulated by an action level of aerobic capacity that was evaluated by energy consumption during work. Thus, the maximum acceptable weight of lifting (MAWL) has been used to estimate the appropriate work load for a workday of 8 and $12 \mathrm{hr}$ during lifting work of 20 to $30 \mathrm{~min}^{22,36)}$. Gallagher ${ }^{37)}$ studied the MAWL on workers, such as underground coal miners, under restricted burden conditions, and emphasized the lowering of MAWL for awkward postures such as those of kneeling and stooping, comparing their data with that of asymmetric lifting reported so far. He also compared the effect of symmetric postures with that of asymmetric ones, using physiological indexes such as $\mathrm{EMG}^{38)}$. Genaidy et al. ${ }^{39)}$ reported the spinal compression tolerance limit (SCTL) in which the compressive strength on the lumbar spine was evaluated easily by regression equation using the published data on age, gender, spinal components and body weight. Compressive strength (CS) is given by the following equation:

$$
\begin{aligned}
\mathrm{CS}= & -13331.2-\left(73.7^{*} \text { age }\right)-\left(962.6^{*} \text { gender }\right) \\
& +\left(403.0^{*} \mathrm{LMS}\right)+\left(79.8^{*} \mathrm{BW}\right)
\end{aligned}
$$

where age is expressed in years, gender as male $=1$ and female $=2$ and the lumbar motion segment (LMS) as $\mathrm{L}_{1}$ $\mathrm{L}_{2}=44, \mathrm{~L}_{2}-\mathrm{L}_{3}=45, \mathrm{~L}_{3}-\mathrm{L}_{4}=46, \mathrm{~L}_{4}-\mathrm{L}_{5}=47, \mathrm{~L}_{5}-\mathrm{S}_{1}=48$. However, the occurrence of LBP resulting from the lifting of materials weighing 20-29 kg cannot be explained only in terms of material weight. Rather, LBP might be caused by a combination of weight and other risk factors such as twisting or other kinds of unnatural, controlled working postures. In order to apply MAWL in the mechanized workplace of today, the load variables with their multipliers should be incorporated, and the characteristics of the mechanization, work procedures, and other conditions should be taken into account.

\section{Asymmetric Lifting of Heavy Materials}

Experimental and field studies have focused on asymmetric lifting motions, e.g., the lifting of materials with one hand while twisting the torso, as a workplace factor of $\mathrm{LBP}^{40-44)}$. In the revised NIOSH guidelines $(1991)^{45,46)}$, the asymmetric variable was added to the above-mentioned six variables, including variables for gripping and hand-holding used during symmetric lifting. The former six variables delineate the main components of the NIOSH action level. Unnatural postures such as bending and twisting induce mechanical shear stress on the lumbar column structure, thus causing the hazard involved in lifting materials at work to vary. Indeed, the movable range of the spinal column during rotation is especially small ( $1 \%$ segment) in the lumbar spine, compared with the range in the cervical or thoracic levels $(3 \% \text { segment })^{47)}$. Because the actual handling of materials at the workplace involves the assumption of asymmetric postures, the total work load should be corrected by an asymmetric multiplier. Garg and Badger ${ }^{48)}$ studied the effects of asymmetric lifting on psychophysically determined acceptable weights, and maximum voluntary isometric strength. They then recommended correction factors of $7 \%$, 
$15 \%$ and $22 \%$ for maximum acceptable weight and $12 \%$, $21 \%$ and $31 \%$ for static strength during $30^{\circ}, 60^{\circ}$ and $90^{\circ}$ of asymmetric lifting. Mirras and Mirka ${ }^{49}$ reported a maximum decrease in trunk torque of $8.5 \%$ for every 15 degrees of asymmetric trunk angle at $\mathrm{L}_{5}-\mathrm{S}_{1}$ spinal levels. Furthermore, Genaidy et $a l .{ }^{23)}$ examined the effects of muscle training on endurance time and suggested its difference on the effects between symmetric lifting task by $248 \%$ increase and asymmetric lifting tasks by $46 \%$ increase. Lavender ${ }^{50)}$ and his associates ${ }^{51)}$ clarified that an asymmetric posture decreased psychophysical lifting capacity by $7 \%$ to $22 \%$ and coactivated the trunk musculature noticeably within a range of 45 degrees of the midsagittal position, as well as the antagonistic muscles in the load direction of greater than 45 degrees. Furthermore, Vink et al ${ }^{52)}$ reported important experimental evidence that a change in the position of the head brings about a change in the right-left balance of EMG discharge in the lumbar muscles. From the evidence, it can be inferred that the asymmetric manual material handling resulting from the nervous control of postural muscle contraction produces shear force across the disc through an increased load on one side and a concomitantly decreased load on the other side. Gallagher and Hamrich ${ }^{38)}$ observed an increase in anterior-posterior and lateral shear force on the $\mathrm{L}_{3}$ level of the lumbar spine and a coactivated recruitment of ancillary muscles during asymmetric lifting, suggesting that the injury to these weak muscles causes LBP.

\section{Progress in the Study of Dynamic Load on the Lumber Spine}

Various research approaches have been taken to investigate the workplace factors of LBP and to establish a marginal workload safety level to prevent LBP. The findings of these studies can be classified into the following categories: (1) characteristics of tissue tolerance of the spinal structure, (2) biomechanical responses of the lumbar spine such as shear stress and spinal shrinkage, (3) physiological energy expenditure and its related responses, (4) the effects of environmental factors that modify or augment LBP, (5) questionnaire and test batteries, (6) models to evaluate spinal loads, and (7) individual characteristics affecting the occurrence of LBP.

Table 3 summarizes the research methods, outcome focuses, the evaluations and objectives, and the modeling used to evaluate workload, appearing in the literature dealing with manual material handling. Recent technical developments have made it feasible to skillfully control the external load on the lumbar spine with computerized instruments, to measure internal changes in muscle force and the resulting stress, and to analyze the dynamic motions of workers during manual material handling. Thus, the load characteristics that would cause stress or microinjuries to the lumbar spine have been experimentally determined, as have the physiological functions to protect the lumbar spine from injuries. These achievements are described below.

An EMG recording of eight trunk muscles enabled a precise analysis of both the velocities of trunk torque and the time-course changes in spinal loading during manual material handling ${ }^{41)}$. When pulling and pushing motions were measured in both isometric and isokinetic modes of work with respect to a sagittal plane and lateral planes, at $30^{\circ}$ and $60^{\circ}$, all subjects were found to be strongest when pulling in an isometric mode on the sagittal plane ${ }^{42}$. It was also shown that the lateral bending and twisting motions were reduced by the use of lifting belts when threedimensional torso movements were evaluated with a goniometer ${ }^{50)}$.

Dynamic load of velocity, acceleration and torque of motion on the lumbar spine during isodynamic lifting were evaluated with a computer-aided triaxial dynamometer to determine the range of motion and maximum resistance to flexion/extension, lateral bending, and left-right rotation ${ }^{53}$. Spinal shrinkage was measured with a stadiometer with supports placed at $\mathrm{L}_{3}, \mathrm{~L}_{4}$ and $\mathrm{C}_{4}$ levels before, during, and after work involving static and dynamic manual lifting ${ }^{54)}$.

A dynamic, three-dimensional, multi-segment model was constructed with two AMTI force plates and two Lacon cameras equipped with two mirrors, and the net muscular moment and angular velocity of the trunk were determined at the $\mathrm{L}_{5}-\mathrm{S}_{1}$ level ${ }^{44)}$. It was found that instructing workers on proper load absorption is an effective means of decreasing the risk of injury.

The following studies demonstrated important experimental evidence relating to overloads on the lumbar spine, although insufficient attention has been paid to these results. First, Marras et al ${ }^{55)}$ conducted three-dimensional trunk motion analysis, and reported lifting frequency, load moment, trunk lateral velocity, trunk twisting velocity and trunk sagittal angle as the five high risk factors contributing to work-related LBP. Second, Straker et al. ${ }^{56)}$ argued that the current use of maximum acceptable weight for a single task is not acceptable for estimating the risk involved when tasks are combined. Third, Sommerich et al. ${ }^{41)}$ found through analysis of temporal patterns of trunk muscle activities that additional trunk muscles were contracted simultaneously 
Table 3. Methods and objectives of research for analysis of workloads on the lumber spine

\begin{tabular}{|c|c|c|c|}
\hline & Methods & Outcome focuses & Evaluations and objectives \\
\hline 1) & $\begin{array}{l}\text { Questionnaire }^{1-3)} \\
\text { Field survey }\end{array}$ & $\begin{array}{l}\text { region of pain, onset of pain } \\
\text { age, gender, muscle strength } \\
\text { job type, workplace condition } \\
\text { perception of effort }\end{array}$ & $\begin{array}{l}\text { prevalence of LBP (SF-36, OHS, NHP, Duke, } \\
\text { SIP), risk factors, individual factors, RPE scale, } \\
\text { psychophysical model }\end{array}$ \\
\hline 2) & Oxygen consumption & $\begin{array}{l}\text { total workload } \\
\text { weight, distance to move, } \\
\text { duration, frequency, etc }\end{array}$ & dynamic model (AL, MAL, MAW) \\
\hline 3) & $\begin{array}{l}\text { Heart rate } \\
\text { Blood pressure }\end{array}$ & & \\
\hline 4) & $\begin{array}{l}\text { Pedometer, posimeter, } \\
\text { Trunk flexion analyzer }{ }^{4)}\end{array}$ & $\begin{array}{l}\text { validity of self-reported } \\
\text { questionnaire }\end{array}$ & posture, handling load \\
\hline 5) & $\mathrm{EMG}^{5,6)}$ & $\begin{array}{l}\text { mean power frequency } \\
\text { compressive load, shear stress } \\
\text { velocity, acceleration }\end{array}$ & $\begin{array}{l}\text { load-frequency relation } \\
\text { dynamic model, safety margin (SCTL) } \\
\text { posture (symmetric/asymmetric) } \\
\text { temporal pattern of loading } \\
\text { muscle recruitment }\end{array}$ \\
\hline 6) & IAP & compressive load & \\
\hline 7) & $\begin{array}{l}\text { Video-recording }{ }^{7,8)} \\
\text { Streophotometry9) }\end{array}$ & isodynamic strength & posture (OWAS, ARBED, etc.) \\
\hline 8) & Multiaxial dynamometer 5,10$)$ & shear stress, compressive force & dynamic load (maximum resistance) \\
\hline 9) & Electrogoniometer ${ }^{(1-14)}$ & trunk motion & trunk motion risk factors \\
\hline 10) & Static dynamic strength tester ${ }^{15)}$ & isometric/isokinetic activity & posture, dynamic model (push-pull strength) \\
\hline 11) & AMTI force plate ${ }^{16)}$ & net muscular movement & load absorption \\
\hline 12) & Stadiometer ${ }^{17)}$ & compressive force & spinal shrinkage \\
\hline
\end{tabular}

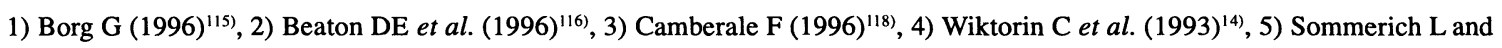
Marras WS (1992) $\left.{ }^{41)}, 6\right)$ Gallagher S and Hamrick CA (1994) $)^{38)}$, 7) Scott GB and Lambe NK $\left.(1996)^{63)}, 8\right)$ Wickstrom G et al. $(1996)^{117)}$, 9) Whistance RS et al. $(1995)^{119)}$, 10) Burdorf A et al. $(1995)^{53)}$, 11) Marras WS et al. $(1995)^{55)}$, 12) Lavender SA $(1995)^{50)}$,

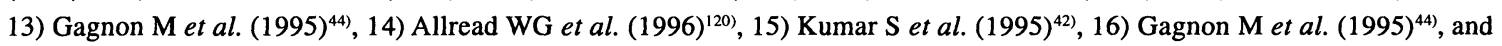
17) McGill SM et al. (1996) ${ }^{54)}$.

under the conditions of speed and loading combination. Fourth, Lavender et al. ${ }^{51)}$ demonstrated by taking EMG recordings of eight muscles around the torso of subjects with asymmetric loads that ispilateral and posterior muscles were simultaneously activated when a workload was directed at greater than $45^{\circ}$. Observing the median power frequency of the EMG results obtained from eight trunk muscles, Kim and Chung ${ }^{577}$ showed that the contralateral side of the muscles to the workload was more strongly activated when an asymmetric posture was assumed. Fifth, Gagnon et al. ${ }^{44)}$ found by analysis of muscular moments and angular velocity of the trunk with a AMTI force plate that supplementary muscular exertions on the trunk muscles could be observed under asymmetric conditions. They emphasized the risk of sudden and unexpected maximal efforts, and called for instruction of workers on the proper load absorption to prevent LBP.

\section{Postural Control at Work}

Stable work postures are essential to ensure both the quality of manufactured goods and the safety of the workplace. During work different kinds of postures are assumed and each induces a different degree of load on the lumbar spine ${ }^{58}$. Investigating 17 selected variables for a self-reported evaluation of postures, Wikforin et al. ${ }^{59)}$ suggested that because a self-reported evaluation of exposure was too crude, a more systematic classification of work postures was necessary. As shown in Table 2, unnatural working postures can be classified into two groups: one involving actions such as bending and twisting, and another involving static muscle contraction such as standing and sitting for long periods of time. The former type includes piling up baggage or bricks, while the latter includes long distance truck driving and standing on an assembly line. These two types of postures 
affect the lumbar spine in the following ways: (1) load resulting from the repetitive movement of intervertebral joints and discs and (2) sustained muscle contraction disturbing peripheral blood flow and causing muscle fatigue. The ergonomic effects of manual material handling on the lumbar spine were examined under dynamic and static postures. Omino and Hayashi ${ }^{60)}$ examined the prevalence of LBP and its relation to dynamic postures among flight attendants by using multidimensional questionnaire III, and identified six postures responsible for LBP. Furthermore, they pointed out that LBP occurred frequently when an unexpected workload was imposed on the lumbar spine, and experimentally demonstrated that the lumbar muscles are not often activated fast enough to cope with the loading that results from an increase in body sway.

Static posture is maintained by sustained muscle tone, especially the activity of paravertebral deep muscles. These muscles, which mainly include type I or red muscles, are characterized by slow contraction and resistance to fatigue ${ }^{61)}$.

Various systems for evaluating the loads of working postures have been introduced at actual workplaces to improve production lines and office workstations. These systems include an Ovak Working Posture Analysis System (OWAS) ${ }^{58,62-64)}$, Arbeitswissenschaftliches Erhebungsverfahren zur Tätigkeitanalyse (ARBED) $)^{65)}$, and Toyota's Verification of Assembly Lines (TVAL) ${ }^{66}$. These evaluation systems make use of biomechanical models based on the lever principle to support the manual handling of materials and its combination with unnatural postures, muscle strength, and the weight of the material being handled. These systems rate the elements of motion such as degree of arm extension, bending angle of arms and legs, and the degree of trunk twisting ${ }^{63,65,66)}$.

Studies on the nervous control of muscle contraction have recently progressed with development of EMG recordings with noiseless amplifiers. Fine postural adjustment is necessary to ensure that work is done safely and efficiently. In order to maintain a stable posture with the head and torso upright, all postural muscle tones must be integrated by systemic postural reflexes, including the stretch reflex, lumbar reflex, tonic neck reflex, tonic labyrinth reflex, and other kinds of related reflexes ${ }^{67,68)}$. Fukuda ${ }^{69)}$ and Tokizane $e t$ $a l .^{70)}$ reported that these reflexes were observed with a maximum effect in adults playing some sports. Postural adjustment is achieved by means of both anticipatory or feedforward response and compensatory or feedback reflex ${ }^{67,71)}$. Cordo and Nashner ${ }^{71)}$ demonstrated these postural maitenance mechanisms by an EMG study of voluntary pushing and/or pulling movements. Because unconsciously elicited postural reflexes form basic patterns of actions, sudden and unexpected changes in posture can cause overloads on the structure of the low back. For this reason, workers must take precautions and be aware whenever they initiate such movements in order to prevent low back injuries ${ }^{72)}$. Such precautions were emphasized in the new Japanese guidelines issued in $1994^{12)}$.

\section{Real Time Analysis of Working Actions}

The recent development of new methodologies has allowed the real-time analysis of motions at work. The actions and motions of workers involved in nurseries ${ }^{73-75)}$, institutions for elderly ${ }^{76)}$, handicapped and infants $\left.{ }^{75}, 76\right)$, garbage collection $^{77)}$, construction ${ }^{78}$, assembly lines, long distance truck driving and cooking facilities ${ }^{79,81)}$ have been analyzed. The focus was centered not only on specific risk factors, but also on combined risk factors sequentially imposed on workers as workloads. The variables of elemental workloads have been reported by Hildebrandt et al ${ }^{80)}$. They include lifting, pulling, pushing, handling of heavy materials, unnatural work postures, cold ambient temperatures, insufficient lighting, and vibration. For example, workers in lunch- supply facilities are engaged in time-sequential jobs consisting of 11 different processes such as prewashing, washing, carrying and rotating with actions involving repetitive use of the upper limbs, lifting, pushing and pulling heavy materials and assuming restrained postures ${ }^{81)}$.

It is necessary to focus on the workplace factors of LBP associated with the temporal sequence of motions at work as a whole, because different temporal sequences of work procedures create different workloads. Hisashige and Koda ${ }^{82)}$ reported a time-course study on the behavior and workloads of truck drivers by measuring work contents, the number of goods carried and their weights, and the working postures taken each minute as well as day-long heart rate monitoring using a Holter ECG. Their results showed that working postures such as bending, twisting, and squatting, and environmental factors such as unstable footing, vibrations, cramped spaces, and outdoor work constitute the principal risk factors of LBP among truck drivers. Truck drivers are exposed to mental stress caused by long-time and longdistance driving in a restricted sitting posture. Moreover, they usually have to deliver baggage from door to door. Given these circumstances, preconditioning such as physical and mental readiness to initiate motions is important for these workers. It is likely to occur that long-distance driving in a 
restricted sitting posture causes not only stiffness of the body trunk due to the increased muscle tone but also the functionally impaired control of muscle contraction due to stimulation of the semicanal apparatus ${ }^{83)}$. Manual handling of heavy materials is a high risk factor of LBP, especially for drivers, because the resulting weakened muscle tone causes fatigue and injury to the vertebral column structures. The prevalence rate of LBP among garbage collectors is extraordinarily high, especially among workers engaged in stacking garbage containers, because they are exposed to cold outdoor weather for a long period where standing by ${ }^{77,84)}$. Therefore, when work involving manual handling of materials is begun in cold weather, workers may be more susceptible to LBP.

McAtamney and Corlett ${ }^{17)}$ emphasized the hazardous nature of nursing work in the health care industry, and argued for the importance of a systematic assessment of the workloads, postures, and the environment. Nurses' workloads consist of the weight and size of objects, resistance to movements (e.g., the force needed to push or pull), the positioning of the upper extremities, irregular start and endpoints of lifting, and difficult accessibility to the object for kneeling and for vision. They also pointed out five important items for assessing nurses' workload, i.e., task, worker, workplace, job design, and organization. Recent developments in the field of ergonomics have urged the intervention of management in building teams, flat organization, and the training of workers skill to ensure their health and safety ${ }^{85)}$. Garg and Beller ${ }^{86)}$ pointed out the special problems that hospital nurses face when caring for bedridden patients. In this context, Mathiassen and Winkel ${ }^{87}$ argued that the usual work-rest is not sufficient. Preconditioning for initiating a motion is important for preventing LBP.

The new guidelines issued by the Jaspanese Labor Ministry in 1994 emphasized that physical exercise, which increases the flexibility of the joints, is more important prior to the handling of heavy materials than is mere rest. Setting standard working schedules in workplaces is also recommended in the new guidelines, which involves establishing standards for working hours, loads and procedures according to the characteristics of the work, and the supplemental devices available, and the experience of the workers.

\section{Environmental and Other Factors of LBP}

Cold Environment: A field study conducted by Tanaka and Yoshida ${ }^{88-91)}$ showed that workers in cold environments complained of LBP most frequently, followed by the common cold, neuralgia, and rheumatic disease. Miura ${ }^{92)}$ also reported a high prevalence rate of LBP (33.3\%), followed by the common cold (27.9\%) and cold sensation in the feet (23.3\%) among workers in cold storage rooms. These field studies indicate that LBP is a commonly observed disorder among workers in cold environments, but the underlying mechanism cannot be explained solely by the biomechanics involved in manual handling of materials. Therefore, we should explore other possible mechanisms to explain why LBP is more likely to occur in cold environments.

ACGIH recognized the appearance of cold shivering as a clinical sign of critical cold exposure ${ }^{93)}$. Muscle tone is elevated, leading to cold shivering which eventually generates heat. This response affects work efficiency since it causes stiffness of the muscles. The lowering of the core temperature and cold stimuli received from cutaneous cold receptors in cold environments provoke a simultaneous contraction of skeletal muscles, causing joints to freeze and rhythmic patterns to develop in burst EMG discharges. When we record the action potential in the filament of the ventral root during cold shivering, motor nerve action potentials are observed as a reciprocally discharged pattern of alpha-gamma linkage, as shown in Figure 195). Therefore, stiffness of the trunk and impaired control of muscle contraction in cold

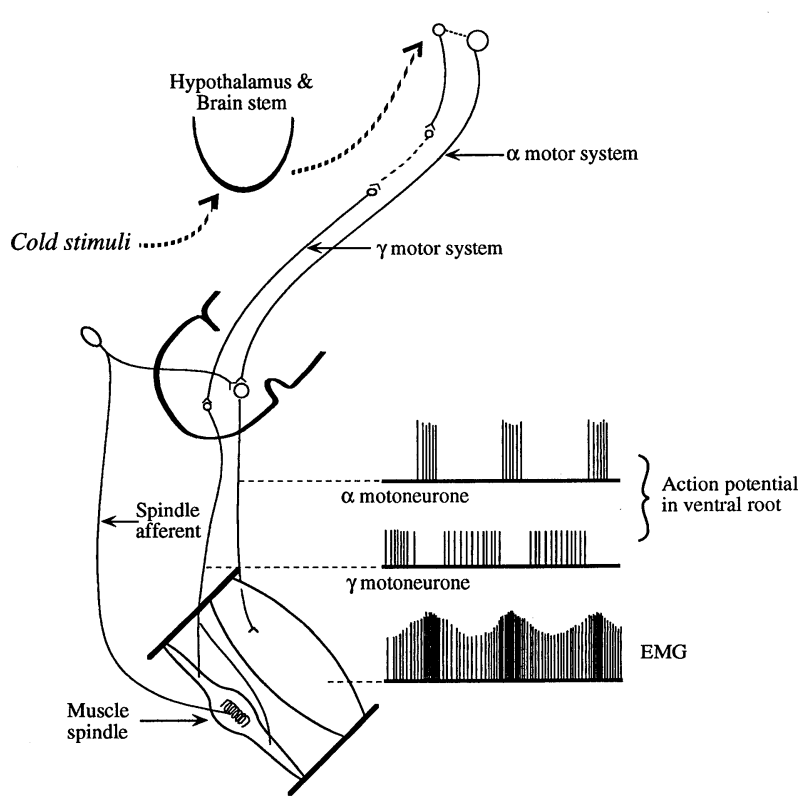

Fig. 1. An efferent motor system to maintain muscle tone The activation of the gamma-motor system increases muscle tone to support posture with coactivated normal alpha-gamma linkage. A lack of coordination in alpha-gamma linkage appears during cold shivering, which affects regulated muscle contraction at work. 
working environments may cause excessive loads on the lumbar spine. Reviewing the effects of cold on task performance, Enander ${ }^{96)}$ pointed out that task proficiency decreases while first a hand, then both hands, and finally the whole body was cooled. Functional impairment of manual performance and dexterity in cold environments may cause awkward handling of materials which could lead to accidents or injuries in workplaces requiring rapid and precise manual activity. Because our understanding of these factors is still limited, it is recommended that any reasonable management program be employed to prevent the injuries and illness in extreme temperature conditions ${ }^{94)}$.

Vibration: In several epidemiological studies, the health effects of vibrations in workplaces have been examined as a possible risk factor of $\mathrm{LBP}^{97-101)}$. The quantitative exposureeffect relationship is not known at present, and the underlying mechanisms have yet to be clarified. The exposure limit of the International Standards (IS 2631) ${ }^{102)}$ is more a minimum requirement for workplaces than a reliable standard for protecting health ${ }^{104}$. Prolonged exposure to vibration was reported to cause a degeneration of intervertebral discs ${ }^{99}$, but experimental and intervention studies must be conducted to clarify the causative relationship between vibration and degeneration. In order to determine the dose-effect relationship, it is of primary importance to determine the transmissibility of external vibration energy into the vertebral column. Kanada et al. ${ }^{105)}$ found that when adults were exposed in a sitting posture to vibration energy of $1 \mathrm{~m} / \mathrm{s}^{2}$ with a frequency range of $1-100 \mathrm{~Hz}$, resonance and absorption of vibration energy were observed, depending on the level in the vertebral column from the pelvic bone to the head.

In addition to such physical effects, an increase in muscle tone due to the tonic vibration reflex may also contribute to the detrimental effects of vibration on the vertebral column, but further studies will be needed to establish the mechanism.

Lighting: Lighting conditions in workplaces are an important factor in postural regulation. Low lighting conditions may cause slip/fall accidents and LBP, especially among elder workers ${ }^{107}$. The dynamic equilibrium of an upright posture is controlled by ascending sensory input such as visual, labyrinth, proprioceptive, tactile and skin pressure sensory inputs ${ }^{67)}$. Among these various inputs, the visual signal is the most important for balancing the posture, as shown by the fact that body sway increases when one's eyes are closed and when the lights are $\operatorname{dim}^{103)}$.

Due attention should be paid to the design of interiors and lighting in workplaces, since an imbalanced interaction of the sensory signals may lead to an instability of the working posture. Sakellari and Soames ${ }^{106)}$ reported that auditory and visual interaction causes increased body swaying which leads in turn to industrial accidents.

As for floor conditions that may cause slip/fall accidents in workplaces, Myung and Smith ${ }^{107)}$ studied the effect of floor contaminants on carrying parameters by measuring slip resistance, and observed an abnormal gait pattern on oily floors because subjects adjusted their stride to secure their balance.

Circulation: Circulatory strain resulting from the handling of materials was examined as a function of lifting posture, weight of materials and handling frequency ${ }^{109,110}$. Although the elevation of intra-abdominal pressure (IAP) during manual material handling relieves the compressive pressure on the vertebral column from the standpoint of biomechanics, an elevated IAP induces circulatory strain by impeding venous return ${ }^{111}$. A remarkable increase in IAP was observed when materials were lifted in restricted postures such as when the worker was squatting, bending, stooping, or kneeling ${ }^{111}$.

The exertion of a maximum effort to lift materials caused experimental subjects to hold their breath, which caused a decrease in the cardiac output and a simultaneous increase in heart rate and blood pressure ${ }^{112}$. Rafacz and McGill ${ }^{13)}$ reported that the increased diastolic pressure resulting from wearing a back belt could be hazardous to older workers with cardiovascular disease. Therefore, sufficient attention should be paid to health care and to the practice of wearing back belts, especially in the case of older workers with workrelated diseases such as cardiovascular and musculoskeletal diseases or obesity.

Smoking: Cigarette smoking is also thought to increase the risk of LBP because smoking causes frequent coughing, resulting in sudden overloads on the lumbar spine, and decreases the diffusion of nutrients into intravertebral discs ${ }^{100}$. These findings suggest the importance of quality of life and of total health promotion plans to prevent LBP in workplaces.

\section{References}

1) Maximum weight in load lifting and carrying (1983) Occupational Safety and Health Series No. 59, ILO.

2) Ayoub MM (1992) Problems and solutions in manual materials handling: The state of the art. Ergonomics 35, 713-28.

3) Veturi SM, Lakshmi BA, Ganguli AK, Chakrabarti AK (1987) The impact and feasibility of international/ 
national standards in the prevention of musculoskeletal injuries in developing countries. Ergonimics 30, 40510.

4) Edwards FC (1987) Prevention of musculoskeletal injuries in the workplace. National approaches to safety standards: Great Britain. Ergonomics 30, 411-7.

5) Work practice guide for manual lifting (1981) NIOSH.

6) Hidebrandt VH (1995) Back pain in the working population: prevalence rates in Dutch traders and proffessions. Ergonomics 38, 1283-98.

7) Christensen H, Pedersen MB, Sjøgaard G (1995) A national crosssectional study in the Danish wood and furniture industry on postures and manual material handling. Ergonomics 38, 793-805.

8) Rossignol M, Suissa S, Abenhaim L (1988) Working disability due to occupational workers in Quebec. $\mathrm{J}$ Occup Med 30, 502-5.

9) Pizatella TJ, Putz-Anderson V, Bobick TG, McGlothlin JD, Waters TR (1992) Understanding and evaluating manual handling injuries: NIOSH research studies. Ergonomics 35, 945-53.

10) General guidebook on Industrial Health, Labor Standards Bureau, Ministry of Labor of Japan. ed. 1987, 1988, 1989, 1990, 1991, 1992, 1993, 1994, 1995 and 1996 editions. Japan Industrial Safety and Health Association. The English version available for 1994 ed., Tokyo.

11) Kumashita A, Aizawa $Y$, Harada H, Watanabe M, Nakamura K (1997) National survey on accidental low back pain in workplaces. Ind Health 35, 187-193.

12) Guidelines on the prevention of lumbago in the workplace. Labour Standards Bureau Notification No. 547, 1994 (cited from Ind Health 35 (1997), 143-172).

13) Industrial Safety and Health Law 1990. Japan Industrial Safety and Health Association.

14) Wiktorin C, Karlqvist L., Winkel J (1993) Validity of selfreported exposure to work postures and manual material handling. Scand J Work Environ Health 19, 208-14.

15) Yu T-S, Roht LH, Wise RA, Kilian DJ, Weir, FW (1984) Low back pain in industry-An old problem revised. $\mathrm{J}$ Occup Med 26, 517-23.

16) Burdorf A (1992) Exposure assessment of risk factors for disorders of the back in occupational epidemiology. Scand J Work Environ Health 18, 1-9.

17) McAtamney L, Corlett EN (1992) Ergonomic workplace assessment in a health care context. Ergonomics 35, 965-78.
18) Buckle PW, Stabbs DA, Randle IPM, Nicholson AS (1992) Limitation in the application of material handling guidelines. Ergonomics 35, 955-64.

19) The report of the committee for preventive countermeasures to low back pain (1993) Japan Industrial Safety and Health Administration, 13.

20) Dul J, Hildebrandt VH (1987) Ergonomic guidelines for the prevention of low back pain at the workplace. Ergonomics 30, 419-29.

21) Genaidy AM, Asfor SS, Mital A, Waly SM (1990) Psychological models for manual lifting tasks. Appl Ergonomics 21, 295-303.

22) Snook SM (1978) The design of manual handling tasks. Ergonomics 21, 963-85.

23) Genaidy AM, Bafna KM, Sarmidy R, Sana P (1990) A muscular endurance training program for symmetrical and asymmetrical manual lifting tasks. J Occup Med 32, 225-33.

24) Mital A (1992) Psychophysical capacity of industrial workers for lifting symmetrical and asymmetrical loads symmetrically and asymmetrica11y for $8 \mathrm{hr}$ work shifts. Ergonomics 35, 745-54.

25) Anderson GBJ (1981) Epidemiologic aspects on low back pain in industry. Spine 6, 53-60.

26) Hidalgo J, Genaidy A, Karwowski W, Christensen D, Huston R, Stambough, JA (1995) Cross-validation of NIOSH limits for mannua1 lifting. Ergonomics 38, 2455-61.

27) Chen F, Aghazadeh F, Lee KS (1992) Prediction of maximum acceptable weight of symmetric and asymmetric lift using direct estimation method. Ergonomics 35, 755-68.

28) Waters T, Garg A, Putz-Anderson V, Fine L (1993) Revised NIOSH equation for the design and evaluation of manual lifting tasks. Ergonomics 36, 749-76.

29) Straker LM, Stevenson MG, Twomey LT (1996) A comparison of risk assessment of single and combination mannual handling tasks: 1 . maximum acceptable weight measures. Ergonomics 39, 128-40.

30) Status of accidental low back pain in Kanagawa and its countermeasures (1988) Occupational Safety and Health Association of Kanagawa Prefecture (In Japanese).

31) Kumar S, Mital A(1992) Margin of safety for the human back: A probable consensus based on published studies. Ergonomics 35, 769-81.

32) Ekholm J, Arborelius WP, Nemeth G (1982) The load on the lumbo-sacral joint and trunk muscle activity 
lifting. Ergonomics 25, 145-61.

33) Gagnon M, Smyth G (1992) Biomechanical exploration on dynamic modes of lifting. Ergonomics 35, 329-45.

34) Leskinen TPJ (1985) Comparison of static and dynamic biomechanical models. Ergonomics 28, 285-91.

35) Garg A, Be11er DA (1994) Comparison of isokinetic lifting strength with static strength and maximum acceptable weight with special reference to speed of lifting. Ergonomics 37, 1363-74.

36) Mital A (1984) Comprehensive maximum acceptable weight of lift database for regular 8-hour work shifts. Ergonomics 27, 1127-38.

37) Gallagher S (1991) Acceptable weights and physiological costs of performing combined manual handling tasks in restricted postures. Ergonomics 34, 939-52.

38) Gallagher S, Hamrick CA (1994) Dynamic biomechanical modelling of symmetric and asymmetric lifting tasks in restricted postures. Ergonomics 37, 1289 310.

39) Genaidy AM, Waly SM, Khalil TM, Hidalgo J (1993) Spinal compression torerance limits for the design of mannual material handling operations in the workplace. Ergonomics 36, 415-34.

40) Schultz AB, Anderson GBJ, Haderspeck K, Ortengren R, Nordin M, Bjor R (1982) Analysis and measurement of lumbar loads in tasks involving bends and twists. $\mathrm{J}$ Biomechanics 15, 669-75.

41) Sommerich L, Marras WS (1992) Temporal pattern of trunk muscle activity throughout a dynamic, asymmetric lifting motion. Human Factors 34, 215-30.

42) Kumar S, Narayan Y, Bacclus $C$ (1995) Symmetric and Asymmetric two-handed pull-push strength of young adults. Human Factors 37, 854-65.

43) Sanchez D, Grieve DW (1992) The measurement and prediction of isometric lifting strength in symmetric and asymmetric postures. Ergonomics 35, 49-64.

44) Gagnon M, Plamondon A, Gravel D (1995) Effects of symmetry and load absorption of a falling load on $3 \mathrm{D}$ trunk muscular moments. Ergonomics 38, 1156-71.

45) NIOSH Work Practice Guide-User's Mannual (1993).

46) DeClerg NG (1993) NIOSH lifting formula changes scope to calculate maximum weight limits. Occup Health and Safety. February, 45-61.

47) Kapandji IA (1978) The physiology of the joints. Vol. 3 . The trunk and the vertebral column. Churchill Livingstone.

48) Garg A, Badger D (1986) Maximum acceptable weight and maximum voluntary asymmetric lifting.
Ergonomics 29, 879-92.

49) Marras W, Mirka G (1989) Trunk strength during asymmetric trunk motion. Human Factors 31, 667-77.

50) Lavender SA (1995) Effect of lifting belts, foot movement, and lift asymmetry on trunk motions. Human Factors 37, 844-53.

51) Lavender SA, Tsuang Y-H, Hafezi A, Andersson GBJ (1992) Coactivation of the trunk muscles during asymmetric loading of the torso. Human Factors 34, 239-47.

52) Vink P, Daanen HAM, Meijst WJ, Ligteringen J (1992) Decrease in back strength in asymmetric trunk postures. Ergonomics 35, 405-16.

53) Burdorf A, van Riel M, van Wingerden JP (1995) Isodynamic evaluation of trunk muscles and low-back pain among workers in a steel factory. Ergonomics 38, 2107-17.

54) McGill SM, van Wijk MJ, Axler CT, Gletsu M (1996) Studies of spinal shrinkage to evaluate low-back loading in the workplaces. Ergonomics 39, 92-102.

55) Marras WS, Lavender SA, Leurgans SE, Fathallah A, Ferguson SA, Allread WG, Rajulu SL (1995) Biomechanical risk factors for occupationally related low back disorders. Ergonomics 38, 377-410.

56) Straker LM, Stenvenson MG, Twomey LT (1996) A comparison of risk assessment of single and combination manual handling tasks: 1 . Maximum acceptable weight measures. Ergonomics 39, 128-40.

57) Kim SH, Chung MK (1995) Effects of posture, weight and frequency on trunk muscular activity and fatigue during repetitive lifting tasks. Ergonomics 38, 85363.

58) Genaidy A, Barkawi H, Christensen $D$ (1995) Ranking of static non-neutral postures around the joints of the upper extremity and spine. Ergonomics 38, 1851-8.

59) Wikforin C, Karlqvist L, Winkel J (1993) Validity of self-reported exposure to work postures and manual material handling. Scand J Work Environ Health 19, 208-14.

60) Omino K, Hayashi Y (1992) Prediction of dynamic posture and occurrence of low back pain. Ergonomics 35, 693-707.

61) Henneman E (1980) Skeletal muscle. The servant of the nervous system. In: Medical Physiology. 14th ed. ed. by Mountcastle VB, 674-702, CV Mosby Co. St. Louis.

62) Karhu O, Kamsi P, Kuorinska I (1977) Correcting working posture in industry: A practical method for 
analysis. Appl Ergonomics 8, 199-201.

63) Scott GB, Lambe NK (1966) Working postures in a perchery system, using the OVAK working posture analysing system. Appl Ergonomics 27, 281-4.

64) Mattila M, Karwowski W, Vilkki M (1993) Analysis of working postures in hammering tasks on building construction sites using the computerized OWAS method. App1 Ergonomics 24, 405-12.

65) Wagner R (1985) Job analysis at ARBED. Ergonomics 28, 255-75.

66) Iritani T, Koide I, Sugimoto $Y$ (1997) Strategy for health and safety management in an automobile company From the prevention of low back pain to Toyota's verification of assembly line (TVAL) - Ind. Health 35, 249-58.

67) Ghez C (1991) Posture. In: Principles of neural science. 3rd ed. eds. by Kandel ER, Schwartz JH, Jessell TH, 596-607. Elsevier Science Publishing Co. New York.

68) Magnus R (1924) Koerperstellung. 113-47. Springer Verlag, Berlin.

69) Fukuda $T$ (1961) Studies on human dynamic postures from the viewpoint of postural reflex. Acta OtoLaryngo1 Supp1 161, 1-52.

70) Tokizane T, Murao M, OgataT, Kondo T (1951) Electromyographic studies on tonic neck, lumbar and labyrinthine reflexes in normal persons. Jpn J Physio1 2, 130-46.

71) Cordo PJ, Nashner LM (1982) Properties of postural adjustment associated with rapid arm movements. J Neurophysiol 47, 287-302.

72) Ayoub A (1982) Control of mannua1 lifting hazards: 1. Training in safe handling. J Occup Med 24, 573-7.

73) Tabuchi T, Kumagai $S$ (1995) Load on the low back in nursing activities. Digest of Science of Labor 50, 5604 (in Japanese).

74) Knibbe JJ, Friele RD (1996) Prevalence of back pain and characteristics of the physical workload of community nurses. Ergonomics 39, 181-98.

75) Okuno M, Uketa S, Nakaseko M, Tokunaga R (1997) Work and workload of nursing personnel in a nursery school and two institutions for handicapped children. Ind Health 35, 202-11.

76) Fujimura T, Yasuda N, Ohara H (1995) Work-related factors of low back pain among nursing aides in nursing homes for elderly. J Occup Health 37, 89-98.

77) Kumaki $T$ (1995) Occupational Health Education for workers in waste management factories. Occup Health $\mathrm{J}$ 18, 23-30 (in Japanese).
78) Thomas M, Roscrance JC, Zimmerman CZ (1996) Workrelated musculoskeletal disorders in bricklaying: A symptom and job factors survey and guidelines for improvement. Appl Occup Environ Hyg 11, 1335-9.

79) Ono Y, Shimaoka M, Hibuta S, Takeuchi Y (1997) Low back pain among cooks in nursery school. Ind Health 35, 194-201.

80) Hildebrandt VH, Brongers PM, Dul J, van Dijk, Kemper CG (1996) Identification of high-risk groups among maintenance workers in a steel company with respect to musculoskeletal symptoms and workload. Ergonomics 39, 232-42.

81) Huang J, Ono Y, Shibata E, Takeuchi $Y$, Hisanaga $N$ (1988) Occupational musculoskeletal disorders in lunch center workers. Ergonomics 31, 65-75.

82) Hisashige A, Koda S (1991) Working conditions and occupational influences on low back pain among Japanese truck transportation workers. In: Towards human work. eds. by Kumashiro M, Megaw ED. 13344, Taylor \& Francis, London.

83) Yamamoto $S$ (1989) Effects of repeated stimulations of semicanal apparatus on various physiological functions. Proc 62th Annual meeting JPN Soc Occup Health, 75.

84) Kumaki $T$ (1987) A case report of an industrial physician's activity. On low back pain among garbage collecting workers. Occup Health J 10, 89-97 (in Japanese).

85) Winkel J, Westgaard H (1996) A model for solving work related musculoskeletal problems in a profitable way. App1 Ergonomics 27, 71-7.

86) Garg A, Beller D (1994) A comparison of isokinetic lifting strength and maximum acceptable weight with special reference to speed of lifting. Ergonomics 37, 1364-74.

87) Mathiassen SE, Winkel J (1992) Can occupational guidelines for work-rest schedule be based on endurance time data? Ergonomics 35, 253-9.

88) Tanaka M (1991) Health care for workers in cold storage. Occup Health 1991 Aug: 9-15 (in Japanese).

89) Tanaka M, Tochihara Y, Matsui J, Ohnaka T, Yamazaki S, Yoshida K, Yagami T (1979) Status and problems of the work in cold storage from a viewpoint of occupational hygiene with reference to working conditions and health problems. J Sci Labor 55, 1016 (in Japanese).

90) Tanaka M (1992) Health impairments due to physical agents - Cold temperature - Occup Health J 15, 39- 
44 (in Japanese).

91) Sawada $S$ (1996) Several problems in occupational hygienic measures for work in cold environments. Occupational Health Review 8, 193-309 (in Japanese).

92) Miura $T$ (1986) Health effects of work in freezing and cold storage rooms. Digest of Science of Labor 41, 105 (in Japanese).

93) Threshold limit values (TLVs) and biological exposure indices (BEIs) (1995) ACGIH.

94) Dukes-Dobos FN, Bernard TE (1996) Problematic issues in prevention of injuries and illness resulting from exposure to heat and cold stress. App1 Occup Environ Hyg 11, 282-7.

95) Yamamoto $S$ (1990) Effects of cold exposure on the muscle tone. J Physiol Anthropol 9, 243-4.

96) Enander E (1988) Performance and sensory aspects of working cold environments: a rewiew. Ergonomics 27, 365-78.

97) Seidel H, Heide R (1986) Long-term effects of whole body vibration: a critical survey of the literature. Int Arch Occup Environ Health 58, 1-26.

98) Kiellberg A (1990) Psychological aspects of occupational vibration. Scan J Work Environ Health 16 (Suppl 1), 39-43.

99) Hansson T, Holm S (1991) Clinical implications of vibration-induced changes in the lumbar spine. Orthopedic Clinics of North America 28, 247-53.

100) Kelsey J, Golden AL (1988) Occupational and workplace factors associated with low back pain. Occup Med 3, 7-17.

101) Wasserman D. An overview of occupational wholebody and hand-arm vibration. Appl Occup Environ Hyg 11, 266-70.

102) ISO guide for vibration and International Standard. ISO 1978.

103) Yamamoto $S$, Sawada $S$, Nakadate $T$ (1988) Analysis of aging in the body sway. Proc 61th annual meeting JPN Soc Occup Health, 349.

104) Oborne $D$ (1983) Whole-body and hand-arm vibration and international standard. ISO 2631: A critique. Human Factors 25, 55-69.

105) Kanada K, Yonekawa Y, Jonai H (1988) Measurement of vibration transmissibility in sitting posture. Proc 61th annual meeting JPN Soc Occup Health, 320.

106) Sakellari V, Soames RW (1996) Auditory and visual interactions in postural stabilization. Ergonomics 39, 634-48.
107) Myung R, Smith J (1997) The effect of load carrying and floor contaminants on slip and fall parameters. Ergonomics 40, 235-46.

108) Sundermier L, Woollacott MH, Jensen JL, Moore $S$ (1996) Postural sensitivity to visual flow in aging adults with and without balance problems. J gerontol 51, M45M52.

109) Lee Y-H, Chen Y-L (1995) Comparative analysis of the workload in seated and standing horizontal submaximal lifting tasks. Ergonomics 38, 1856-66.

110) Grieve D, Pheasant $S$ (1982) Biomechanics in the body at work. Cambridge Univ Press, London.

111) McGill SM, Norman RW, Sharratt MT (1990) The effect of an abdominal belt on trunk muscle activity and intraabdominal pressure during squat lift. Ergonomics 33, 149-60.

112) Yamamoto S, Maruyama R (1991) Effect of static muscle contraction on systemic circulation. Proc 64th annual meeting JPN Soc Occup Health, 364.

113) Rafacz W, McGill SM (1996) Wearing an abdominal belt increases diastolic blood pressure. J Occup Environ Med 38, 925-7.

114) Cook TM, Rosecrane J, Zimmermann C (1996) Workrelated musculoskeletal disorders in bricklaying: $\mathrm{A}$ symptom and job factors survey and guidelines for improvement. Appl Occup Environ Hyg 11, 1335-9.

115) Borg G (1990) Psychophysical scaling with applications in physical work and the perception of exertion. Scan J Work Environ Health 16 (Suppl 1), 55-8.

116) Beaton DE, Bombardier C, Hog-Johnson SA (1996) Measuring health in injured workers: A cross-sectional comparison of five generic health status instruments in workers with musculoskeletal injuries. Am J Ind Med 29, 618-31.

117) Wickstrom G, Laine M, Pentti J, Hytiainenn (1996) A video-based method for evaluation of low-back load in long-cycle jobs. Ergonomics 39, 826-41.

118) Camberale $F$ (1990) Perception of effort in manual material handling. Scan J Work Environ Health 16 (Suppl 1), 59-66.

119) Whistance RS, Adams LP, Geems BA, Bridger RS (1995) Postural adaptations to workbench modifications in standing work. Ergonomics 38, 2485-503.

120) Allread WG, Marras WS, Parnianpour M (1996) Trunk kinematics of one-handed lifting and the effects of asymmetry and load weight. Ergonomics 39, 322-34. 